\title{
Safety Culture, Policies and Practices in Nigerian Maritime Industry: The Exxon-Mobil Experience
}

\author{
John Nsikan Efiok ${ }^{1}$, Opeoluwa Oluseye ${ }^{2}$, Tommy Uduak ${ }^{3}$, Raimi Olalekan ${ }^{4}$ \\ ${ }^{1}$ Faculty of Business Administration, University of Uyo, Uyo, Nigeria \\ ${ }^{2}$ Warsash Maritime Academy, Southampton Solent University, Southampton, UK \\ ${ }^{3}$ Faculty of Management Sciences, University of Calabar, Calabar, Nigeria \\ ${ }^{4}$ Department of Environmental Health Management, University of Uyo, Uyo, Nigeria \\ Email: ${ }^{\text {nsikiboy5000@yahoo.com }}$
}

Received 19 April 2015; accepted 10 August 2015; published 13 August 2015

Copyright (C) 2015 by authors and Scientific Research Publishing Inc.

This work is licensed under the Creative Commons Attribution International License (CC BY).

http://creativecommons.org/licenses/by/4.0/

(c) () Open Access

\begin{abstract}
Over the years, issues on safety culture and policies in maritime industry have received widespread research attention. Some maritime firms have even gone further to anchor their safety policies on learned corporate culture. However, whether these policies are fully embraced and complied with by seamen is a different kettle of fish altogether. This study therefore, examines safety culture, policies and practices in Nigerian maritime industry with a view to ascertaining: the extent of freight men' awareness and compliance to safety policies, identifying hindrances to conformity with safety policies and practices, and determining intervention options that management of Exxon-Mobil could use to foster safety compliance. The study adopts a survey approach, with structured questionnaire, and gathering primary data from seamen onboard. The findings reveal that workers are aware of the various safety policies and practices put in place by management, but adherence is impeded by several factors-inadequate staff strength, crew fatigue, and poor wages. Others include contract labour, inadequate safety training, complacency, and high risk tolerance. Surprisingly, improper handover and supervisory interference were not potent enough to hinder compliance with safety regulations at sea.
\end{abstract}

\section{Keywords}

Safety Culture, Marine Vessel, Safety Policy and Strategy, Maritime Industry

\footnotetext{
${ }^{*}$ Corresponding author.
} 


\section{Introduction}

In the global maritime industry, ensuring safety of vessels and crew entails crafting and judiciously implementing sound safety policies and practices. However, the policies and practices necessary to achieve incident-free marine operation must be anchored on the culture of work safety prevailing in the firm at any given time. Culture is the acceptable social norms, values, and behaviour pattern of the people in a particular setting or work group, it is imperative for learning and act as a source of solving groups' problem. According to [1], culture is a series of social assumptions considered valuable to be taught to new members as a correct way to perceive, think and feel, in relation to group's problems. Thus, safety culture can be visualized as series of values, beliefs, customs, and norms about a phenomenon affecting the safety of work group. It is associated with the manner of behaviour, and appropriate attitudes in marine environment. Workers' perception of safety in the work place can be positive, negative or neutral, and when learned and appropriately internalized, safety culture creates a climate that influences how well people plan, communicate and make decisions concerning their health and safety on board.

Policy is a definite course or strategy selected by individuals, government agencies or private organizations from among alternatives to guide and usually determine present and future decisions [2]. Thus, policies exist to serve as a guide to appropriate action that may be needed to achieve expected results. In practical terms, safety policy consists of courses of actions and measures deliberately taken by shipping firms or its agents to direct the affairs of its people (all categories of seafarers) towards the minimization of vessel accidents and crew injuries [3]. Thus, once a safety policy is conceived to meet an end, its cycle has been kick-started. However, the extent by which marine safety policy can be adjudged to have failed or succeeded is among other factors dependent on the extent of awareness of sea workers whose support and compliance is sought in the first place, hindrances to compliance, and the safety culture interventions/initiatives of management particularly regarding compliant enforcement.

It may be argued that a company that upholds higher level safety cultures has the tendency to be committed to workers' and client safety as a strategic priority. The commitments so displayed also translate to actions and attitudes which are evident throughout the organization [4]. Apart from industry efforts to contend vessel and crew accidents, safety culture in maritime business have received empirical consideration in so many other ways. But there are clearly some issues which still need special attention. For instance, in a bid to prevent damage to vessels, cargo and crew injuries, management intervene by putting in place safety policies and regulations. However, crew awareness of applicable safety regulations, crew compliance behavior, and the factors that may make or mar compliance among others, have not been given thorough empirical examination and documentation. Though these issues are often expressed marine safety literature, they are rarely actually studied in depth.

When accident occurs, the extent of damage may range from less damage to vessel and cargo to entire damage to cargo, massive crew injuries and even death [5]. Accordingly, vessel safety policies and regulations as well as their enforcement seek to prevent and reduce the severity of vessel accidents. To that extent, vessel safety rules and regulations are enacted and enforced by signatory nation states. Policy and regulatory enactment have an acknowledged impact on safety performance, but excellence can only be achieved by factoring purposeful interventions and awareness into the organizational culture. Therefore, it is necessary to connect methodologies of safety management to the prevailing organizational culture.

In general, this study therefore examines firms' safety policies with emphasis on prevailing safety culture in maritime industry. Consequently, the study sought to achieve the following specific objectives. To:

1) Examine the extent of awareness of and compliance with safety culture policies and practices in Exxon-Mobil Company.

2) Identify the hindrances to conformity with safety policies and practices in Exxon-Mobil Company.

3) Assess the Initiatives/interventions by management of Exxon-Mobil to foster safety culture and policy compliance.

The following research questions are applicable:

1) To what extent are staff aware and comply with safety policies and practices in Exxon-Mobil Company?

2) What are the hindrances to conformity with safety policies and practices in Exxon-Mobil Company?

3) What intervention options exist for management of Exxon-Mobil to foster safety culture and policy compliance?

Apart from the introductory aspect, the remaining part of this report is structured as follows: Section two discusses theoretical issues in the safety literature, section three describes the methodological blueprint through 
which the study was carried out and documented, and in section four, we present results of data analysis and discuss the findings, drawing applicable implications where necessary. The study is brought to conclusion in section five

\section{Theoretical Framework}

\subsection{Corporate Culture}

According to [6], culture is "a complex framework of national, organizational, and professional attitudes and values within which groups and individuals function." Corporate culture is often referred to as the glue that holds an organization together by socializing workers in a way that increases commitment to the goals of the entity [7]. It embodies the philosophy of top management, which is translated into, and affects the behaviors of employees. Although some schools of thought focus on the role of executives, others note that middle management likely plays a substantial role as well, conveying the culture to front-line workers in any organization [8].

Culture is critical to understanding any society or group [9]. It can be viewed as the sum total of the attainments and activities of any specific period, race or people. Through the process of socialization, individuals align into groups while groups have the capacity to shape, influence, and determine members' perception, inputs, attitudes and indeed behaviours [10]. [11] asserts that organisational culture is the collection of values and norms that are shared by people and groups in an organisation and what control the way they interact with each other and with stakeholders outside the organisation. This therefore implies that organisational culture is the fundamental assumption that guide and determine how organization solves their problem. [12] are of the view that organisational culture is one of the factors responsible for corporate effectiveness. [13] identified organizational culture as the basis for the differences among Organisations. Culture provides stability to an organization and it gives employees a clear understanding of 'the way things are done around the organization [14]. Hence, it is very important that employees learn the existing culture of an organisation in order to achieve success.

\subsection{Safety Culture}

While an exact definition of a safety culture does not exist, a recurring theme in the literature is that organizations with effective safety cultures share a constant commitment to safety as a top-level priority, which permeates the entire organization. Accordingly, the following dimensions of safety culture are noticed in the literature 1) acknowledgment of the high risk, error-prone nature of an organization's activities, 2) blame-free environment where individuals are able to report errors or close calls without punishment, 3) expectation of collaboration across ranks to seek solutions to vulnerabilities, and 4) willingness on the part of the organization to direct resources to address safety concerns [4]. Based on extensive field work in multiple organizations, [13] have observed several common, cultural values in safety enhancing organizations: "interpersonal responsibility; person centeredness; [co-workers] helpful and supportive of one another; friendly, open sensitive personal relations; creativity; achieving goals, strong feelings of credibility; strong feelings of interpersonal trust; and resiliency[7].”

Researchers have not also reached a consensus on the dimensions that constitute a safety culture. Studies have however identified safety culture dimensions ranging from management to risk awareness [15] and attitudes and perceptions of the safety climate. A dissertation on predictors of work-related injuries in the maritime industry cited dimensions of a positive safety culture to include: "commitment by management and workforce, leadership style and communication, individual responsibility, management responsibility, risk awareness and risk-taking” [16].

According to [6], the aspect of organizational safety culture that may be visible or measurable is sometimes referred to as the safety "climate," which includes management systems, safety systems, and individual attitudes and perceptions. Maritime organizations are now adapting safety culture and climate surveys from other industries to benchmark and identify potential deficiencies in their unique safety culture. Such safety culture surveys take into consideration several input variables such as production pressures, risk tolerance, communication lapses, and safety consequences on morale and performance. In this direction, [7] noted that previous work in assessing organizational culture effects on total quality management, and organizational culture in high reliability organizations may also be pertinent to efforts to measure culture and its consequences for safety at sea.

\section{Materials and Procedures}

The study employed a survey design. This type of design allows generalization to be made from large popula- 
tion when representative samples are drawn. Survey design was used in this study for its economy, rapid data collection and ability to understand the characteristics of the population under study [17]. The fact that this study is quantitative in nature, and involves an attempt to describe the safety culture policies and practices in Exxon Mobil Nigeria made the use of descriptive survey design appropriate for this study. Exxon-Mobil is one of the largest oil producers in Nigeria. It operates a joint venture agreement with the Federal Government of Nigeria, through the Nigerian National Petroleum Corporation (NNPC).

The survey approach involved using structure but self-design questionnaire as the research instrument to gather data from the relatively large population of Exxon-Mobil questionnaire. Data collection was mainly from primary source using the questionnaire augmented with pieces of information from periodicals, journals and other internal materials from the firm. Items in the questionnaire were drawn from the extensive maritime safety literature examined throughout the study thus, ensuring high level of instrument reliability and scale validity.

The targeted population consisted of all seagoing employees including engineers working at Exxon -Mobil oil prospecting floating vessel in Nigeria, and simple random sampling technique was used to draw sixty two (62) respondents as sample size for this study. The respondents comprised forty two (42) junior level engineers, marine deck personnel and seamen, 6 shift supervisors, 5 top level managers, and 7 auxiliary contract employees. Among the 62 respondents, 12 either could not complete their questionnaire on schedule or were not accurate in answering the questions as required. Thus, the remaining 50 copies of the questionnaire were found useful for data analysis. Data was analyzed using frequency count and percentages supported with charts to enhance lucid analysis and interpretation. Data collected were processed through the use of statistical package for social science (SPSS) version 20.

\section{Results and Discussion}

\subsection{Socio-Demographic Characteristics}

In terms of socio-demographic characteristics of respondents, Table 1 shows that 47 male and 3 female respondents participated in the study adding up to 50 respondents. From the 47 male respondents, 7 (14\%) were between 20 - 30 years, 28 (56\%) were between the ages of 31 - 40, 10 (20\%) respondent was between age 41 - 50, and 2 (4\%) were 51 - 60 years old. Similarly, Out of the 3 female participants in this study, 1 (2\%) was between the age of 20 - 30 years, and were 2 (4\%) were between the ages of 31 - 40. Other age groupings had no female respondent. This implies that the study was made up of more male than female respondents, and majority of respondents (both male and female) were between 30 - 40 years. The low percentage of female maritime workers in the company raise crucial concern as workplace safety issues has been shown to be amenable to gender sensitivity. Female workers are generally regarded to be temperate in matters involving safety at workplace [18].

Table 2 shows cross tabulation of the respondents' educational qualification and length of work experience. It is clear from the Table that graduates with HND, B. Sc or B.A degree constituted the highest number (29) of respondents in the study while OND/NCE certificate holders were 14 and Master degree holders were seven participants. This is an indication of the fact that the study was carried out among highly educated groups of people who were expected to make meaningful contributions to solving the problem at hand. Similarly, 19 (38\%) respondents had between 1 - 5 years working experience, 20 (40\%) had between 6 - 10 years of work experience with the organization, and 11 (22\%) respondents has work with the organization between 11 - 15 years. Thus, majority of respondents has a good number of years of working experience necessary to understand the subject

Table 1. Age of the respondents classified by their sex.

\begin{tabular}{rrrccccc}
\hline & & & \multicolumn{2}{c}{ Age of respondent } & \multicolumn{2}{c}{ Total } \\
\cline { 3 - 7 } & & & $20-30$ yrs & $31-40$ yrs & $41-50$ yrs & $51-60$ yrs \\
\hline \multirow{2}{*}{ Respondent's Sex } & Male & Frequency & 7 & 28 & 10 & 2 & 47 \\
& & Percent & $14 \%$ & $56 \%$ & $20 \%$ & $4 \%$ & $100.0 \%$ \\
& \multirow{2}{*}{ Female } & Frequency & 1 & 2 & 0 & 0 & 3 \\
& & Percent & $2 \%$ & $4 \%$ & $0.0 \%$ & $0.0 \%$ & $100.0 \%$ \\
& & Frequency & 8 & 30 & 10 & 6 & 50 \\
& & Percent & $16.0 \%$ & $60.0 \%$ & $20.0 \%$ & $12 \%$ & $100.0 \%$ \\
\hline
\end{tabular}

Source: Author's compilation from field survey, 2015. 
matter of the study and to contribute meaningfully.

Table 3 shows distribution of respondents according to work position. Results indicate that $6 \%$ of respondents were ship managers, $12 \%$ were supervisors, $8 \%$ were crew engineers, and $6 \%$ were specialist/advisors. Similarly, $36 \%$ of participants in the survey were onboard operators/technician, $4 \%$ are mechanic, $6 \%$ were deck foreman on shift, $16 \%$ were crane operators and $10 \%$ were marine deck personnel working in the Exxon-Mobil floating vessel. Thus, many work position were considered while carrying out the study. As the study cut across different job specification and position, the credibility and generalization of findings is enhanced [17].

\subsection{Extent of Awareness and Compliance with Safety Measures}

Awareness and compliance to safety policies and practices is essential to marine safety performance. Consequently, we sought to find out the extent of workers awareness to safety policies and practices overtime in Exxon Mobil. Results are presented on Table 4.

It can be observed that most respondents were aware of the numerous safety policies and practices commonly in operation in the surveyed organization. For instance 32\% majority of respondents were aware of the use of safety induction video to monitor safety related operations carried out by employees. In like manner, $16 \%$ were familiar hazard identification, and $12 \%$ were familiar with loss prevention. It is noted that the least familiar principles were those related to use of vessel safety manual, Vessel Trim and Stability Booklet, and use of personal Protective Equipment with $4.0 \%$ of respondents each claiming knowledge and familiarity. This implies that the extent to which marine employees adhere to safety regulations on board may depend on the level with which they are aware of existing safety culture policies and practices. Accordingly, management is encouraged to ensure increased awareness on some of the safety policies shown not to be popular with marine workers.

Table 2. Educational qualification of respondent classified by their length of marine work experience.

\begin{tabular}{|c|c|c|c|c|c|c|}
\hline & & & \multicolumn{3}{|c|}{ Respondents' years of experience } & \multirow[t]{2}{*}{ Total } \\
\hline & & & $1-5 \mathrm{yrs}$ & $6-10$ yrs & $11-15$ yrs & \\
\hline \multirow{6}{*}{ Respondent's Educational Qualification } & \multirow{2}{*}{$\mathrm{OND} / \mathrm{NCE}$} & Frequency & 6 & 5 & 3 & 14 \\
\hline & & Percent (\%) & $43 \%$ & $36 \%$ & $21 \%$ & $100.0 \%$ \\
\hline & \multirow{2}{*}{ HND/B.Sc/B.A } & Frequency & 12 & 10 & 7 & 29 \\
\hline & & Percent (\%) & $41 \%$ & $35 \%$ & $24 \%$ & $100.0 \%$ \\
\hline & \multirow{2}{*}{ M.Sc/MBA } & Frequency & 1 & 5 & 1 & 7 \\
\hline & & Percent (\%) & $14 \%$ & $71 \%$ & $14 \%$ & $100.0 \%$ \\
\hline \multirow{2}{*}{ Total } & & Frequency & 19 & 20 & 11 & 50 \\
\hline & & Percent (\%) & $38 \%$ & $40 \%$ & $22 \%$ & $100.0 \%$ \\
\hline
\end{tabular}

Source: Author’s compilation from field survey, 2015.

Table 3. Work position of respondents

\begin{tabular}{|c|c|c|}
\hline Job position & Frequency & Percentage \\
\hline Manager & 3 & 6 \\
\hline Supervisor & 6 & 12 \\
\hline Engineer & 4 & 8 \\
\hline Specialist/Advisor & 3 & 6 \\
\hline Operator/Technician & 18 & 36 \\
\hline Mechanic & 2 & 4 \\
\hline Deck foremen & 3 & 6 \\
\hline Crane Operator & 8 & 16 \\
\hline Marine Deck Personnel & 5 & 10 \\
\hline Total & 50 & 100 \\
\hline
\end{tabular}

Source: Author’s compilation from field survey, 2015. 
Table 4. Seafarers' awareness of safety culture policies and practices in exxon mobil.

\begin{tabular}{ccc}
\hline Dimensions & Frequency & Percent \\
\hline Safety Induction Video & 16 & 32 \\
Hazard Identification (U-SEE, U-ACT) & 8 & 16 \\
Loss Prevention Observation (LPO) & 6 & 12 \\
Last Minute Risk Assessment & 5 & 10 \\
Job Intervention Programme & 3 & 6 \\
Step Back 5x5 & 3 & 6 \\
Job Safety Analysis & 3 & 4 \\
Vessel Safety Manual & 2 & 4 \\
Vessel Trim and Stability Booklet & 2 & 4 \\
Personal Protective Equipment & 2 & $\mathbf{1 0 0}$ \\
Total & $\mathbf{5 0}$ & 4 \\
\hline
\end{tabular}

Source: Author’s compilation from field survey, 2015.

\subsection{Hindrances to Conformity with Safety Policies and Practices}

Certain factors may conspire to hinder strict compliance to marine safety policies and regulations at sea. In an attempt to identify these ills with the view to suggesting means of addressing them, Table 5 shows respondents opinion on the hindrances to conformity with safety policies and practices in Exxon-Mobil Company.

On Table 5, respondents give their opinions on the factors that have impeded strict adherence to safety regulations in Exxon Mobil. Among the factors identified, inadequate staff strength (30.0\%) top respondents' suggestions. This is followed by crew fatigue (20\%), and issues of poor wages (16\%). Issues and problem relating to contract labour and inadequate safety training for marine workers occupied the fourth position with $8 \%$ each from respondents. It is also observed that the two factors; improper handover $8 \%$, and under supervisory interference $8 \%$ occupied the bottom of the list, showing that these factor did not receive much consideration from respondents.

In addition, the findings may have suggested that improper handover and supervisory interference were not considered potent enough factors to significantly hinder strict adherence and compliance to safety regulations at sea. One important implication drawn from the findings is the strength of impediment of the top three factors (inadequate staff strength, crew fatigue, and poor wages). Inadequate staffing of vessel has been reported to cause fatigue, sleeplessness, and lack of concentration [10] [13], and has been associated with some of the major accidents in the maritime and other sectors [19]. Work fatigue is dangerous to sea men, the main cause being work overload and has been fingered in many shipwrecks causing injury to crews, damage to property and loss of vessels. Similarly, poor wages is tantamount to service exploitation; it dampens workers' morale and declines commitment. It is one of the causes of unsafe and dysfunctional behavior in the workplace and causes job dissatisfaction. A dissatisfied marine worker is a safety risk to himself, his coworker, and the organization as a whole.

\subsection{Initiatives/Interventions to Foster Safety Culture and Policy Compliance}

Results on Table 6 show various interventions by the company under investigation to enforce awareness and compliance to safety standard. By the results, it can be stated that openness to communication (32.0\%) was given highest priority by respondents. This espouses the need to adequately keep open various lines of formal and informal communication between workers and the employers in the organization. From the results, openness and communication is followed by feedback on safety errors (20\%), support for safety implementation by management (12\%), and support for the injured (12\%). The importance of top management support in enhancing safety compliance can never be overemphasized. Management support is needed in terms of training on safety, safety culture learning, compensation for the injured, ensuring team building and intervention in unsafe acts and behavior. Management support and dedicated participation enhances employee's safety consciousness and lead to internalizing safety policies and programs. 
Table 5. Hindrances to conformity with safety policies and practices in exxon mobil.

\begin{tabular}{ccc}
\hline Dimensions & Frequency & Percent \\
\hline Inadequate staff strength & 15 & 30 \\
Crew fatigue & 10 & 20 \\
Poor wages & 8 & 16 \\
Contract staffing issues & 4 & 8 \\
Inadequate training & 4 & 8 \\
Non availability of spares and work materials & 3 & 4 \\
Complacency & 2 & 4 \\
High risk tolerance & 2 & 2 \\
Improper handover & 1 & 2 \\
Un due interference from superior & 1 & $\mathbf{1 0 0}$ \\
\hline
\end{tabular}

Source: Author's compilation from Field Survey, 2015.

Table 6. Initiatives/interventions to foster safety culture and policy compliance.

\begin{tabular}{ccc}
\hline Dimensions & Frequency & Percent \\
\hline Openness and communication & 16 & 32 \\
Feedback and communication about safety errors. & 10 & 20 \\
Management support for safety implementation & 6 & 12 \\
Management support for the injured & 6 & 12 \\
Culture of learning/improvement & 4 & 8 \\
Crew training and staffing & 4 & 4 \\
Teamwork within units & 2 & 4 \\
Intervention in unsafe acts & 2 & $\mathbf{1 0 0}$ \\
\hline
\end{tabular}

Source: Author’s compilation from field survey, 2015.

\section{Conclusions}

The main thrust of this report was to examine safety culture policies and practices in maritime industry in Nigeria. The focus was Exxon-Mobil incorporated, an international offshore oil prospecting firm based in Nigerian coastal region. To give direction to the study, three specific objectives were considered: Examine the extent of awareness of and compliance with safety culture policies and practices in Exxon-Mobil Company; identify the hindrances to conformity with safety policies and practices in Exxon-Mobil Company; and access the Initiatives/interventions by management of Exxon-Mobil to foster safety culture and policy compliance.

A lot of interesting findings arises from the analysis of data to aid the conclusion of this study. To start with, the study has established that employee awareness is necessary for successful implementation of marine safety regulations. Our study has also found that workers are aware of the various safety culture policies and practices put in place by maritime practitioners in the company. But adherence to these policies is impeded by several factors key among which are inadequate staff strength, crew fatigue, and poor wages. Other factors include contract labour and inadequate safety training for marine workers, complacency, and high risk tolerance. On the other hand, improper handover and supervisory interference were not potent enough to hinder compliance with safety regulations at sea.

This study made significant contributions to marine safety management literature by identifying various intervention and initiative managers can bring on board to ensure safety compliance and robust safety practice. For instance, it has been found that adequate lines of formal and informal communication between workers and the employers in the organization is vital to enhancing safety, reducing marine accidents and minimizing injuries and dead at sea. 
In addition, from the study we conclude that maintaining a system of feedback on safety errors and support for safety implementation by management leads to drastic reduction of marine incident. Furthermore, importance of management support for the injured has been shown to enhance safety compliance, boost morale, and increase satisfaction with the job. Thus, to ensure strict compliance and reduce safety risk in global maritime industry, management support is needed in terms of training on safety, safety culture learning, compensation for the injured, ensuring team building and intervention in unsafe acts and behavior.

\section{References}

[1] Schein, E.H. (2004) Organizational Culture and Leadership. 3rd Edition, Jossey-Bass, San Francisco.

[2] Dess, M., Lumpkin, K. and Eisner, B. (2000) Business Strategy and Performance in Malaysian SMEs: A Recent Survey. Malaysian Management Review, 24, 1-10.

[3] Horck, J. (2004) An Analysis of Decision-Making Processes in Multicultural Maritime Scenarios. Maritime Policy Management, 31, 15-29. http://dx.doi.org/10.1080/03088830310001642021

[4] Frank, W.L. (2005) Essential Elements of a Sound Safety Culture. Process Plant Safety Symposium, Atlanta.

[5] Bloor, M. and Sampson, H. (2009) Regulatory Enforcement of Labor Standards in an Outsourcing Globalized Industry: The Case of the Shipping Industry. Work Employment and Society, 23, 711-726. http://dx.doi.org/10.1177/0950017009344915

[6] Kanev, D. (2005) Seaborne Trade Effects of International Terrorism and Effectiveness of the Anti-Terrorist Policy. Accident Analysis \& Prevention, 40, 594-601.

[7] Håvold, J. (2007) National Cultures and Safety Orientation: A Study of Seafarers Working for Norwegian Shipping Companies. Work \& Stress, 21, 173-195. http://dx.doi.org/10.1080/02678370701424594

[8] Kohn, J.P. and Mark, A.F. (1996) Fundamental of Occupational Safety and Health. Rockville.

[9] Mansell, J. (2009) Choice of Flag State. Flag State Responsibility. Journal of Safety Research, 37, 401-411. http://dx.doi.org/10.1007/978-3-540-92933-8_7

[10] Barsan, E., Surugiu, F. and Dragomir, C. (2012) Factors of Human Resources Competitiveness in Maritime Transport. International Journal on Marine Navigation and Safety of Sea Transportation, 6, 126-130.

[11] Hänninen, M. (2008) Analysis of Human and Organizational Factors in Marine Traffic Risk Modeling (Literature Review). Helsinki University of Technology, Helsinki.

[12] Magramo, M. and Gellada, L. (2009) A Noble Profession Called Seafaring: The Making of an Officer. International Journal on Marine Navigation and Safety of Sea Transportation, 23, 124-154. http://dx.doi.org/10.1201/9780203869345.ch113

[13] Bloor, M., Datta, R. Gilinsky, Y. and Horlick-Jones, T. (2006) Unicorn among the Cedars: On the Possibility of Effective Smart Regulation of the Globalised Shipping Industry. Social and Legal Studies, 15, 537-554. http://dx.doi.org/10.1177/0964663906069546

[14] Baylon, A. and Santos, V. (2011) The Challenges in Philippine Maritime Education and Training. International Journal of Innovative Interdisciplinary Research, 1, 349-356.

[15] Lane, T. (1997) Globalization, Deregulation and Crew Competence in World Shipping in McConville, James (Edit). Transport Regulation Matters, London.

[16] Ding, J. and Liang, G. (2005) The Choices of Employing Seafarers for the National Ship-Owners in Taiwan: An Empirical Study. Maritime Policy \& Management, 32, 123-137. http://dx.doi.org/10.1080/09523980500062643

[17] Sekaran, U. (2001) Research Methods for Business: A Skills Building Approach. 2nd Edition, John Wiley and Sons, Inc., New York.

[18] Galam, R. (2011) Navigating Lives: The Spatio temporality of the Gender Identity, Agency and Subjectivity of Filipino Seamen's Wives. Ph.D. Thesis, Cardiff University, Cardiff.

[19] Benton, G. (2005) Multicultural Crews and the Culture of Globalization. The International Association of Maritime Universities (IAMU) 6th Annual General Assembly and Conference, Malmö. 